\title{
Goalball Sporcularında Ayakkabının ve Görmenin Denge Üzerine Etkisinin İncelenmesi
}

Evaluation of the Effect of Shoes and Seeing on Balance in Goalball Players

\author{
Bihter AKINOĞLU ${ }^{1}$, Tuğba KOCAHAN², Tŭğba BIRBEN ${ }^{1}$, Necmiye Ün YILDIRIM ${ }^{1}$, \\ Adnan HASANOĞLU², Gülcan KARAMAN ${ }^{2}$ \\ ${ }^{1}$ Yıldırım Beyazıt Üniversitesi, Sağlık Bilimleri Fakültesi, Fizyoterapi ve Rehabilitasyon Bölümü, Bilkent Yerleşkesi, Ankara \\ ${ }^{2}$ Gençlik ve Spor Bakanlığı, Spor Genel Müdürlüğü, Sağlık İşleri Dairesi Başkanlığı, Eryaman, Ankara
}

\section{öz}

Amaç: Bu çalışma goalball sporcularında ayakkabının ve görmenin (gözler açık, gözler kapalı) denge üzerine etkilerini belirlemek amacıyla yapılmıştır. Gereç ve Yöntem: Çalışmaya 16-26 yaşları arasında, görme keskinlikleri B1-B3 arasında olan 9 gönüllü bayan goalball sporcusu ile gerçekleştirildi. Sporcuların stabilite ve tek ayak üzerinde denge testleri Human Body Equilibrium 360 (HUBER 360®) ile yapıldı. Ölçümler ayakkabılı ve ayakkabısız olarak yapıldı. Sonuçlar: Ayakkabılı ve ayakkabısız yapılan stabilite testinde merkez, uzunluk ve hız değerlerinde farklılık olmadığı ( $p>0.05)$, gözler açık ölçülen alan değerlerinde farklılık olmadığı $(p>0.05)$ belirlendi. Ancak gözler kapalı alan değerinin ayakkabısız pozisyonda daha az olduğu $(p<0.05)$ ve ayakkabısız ölçüm lehine olduğu belirlendi. Ayakkabılı ve ayakkabısız olarak değerlendirilen sağ ve sol ayak üzerindeki denge değerlerinde farklılık olmadığı belirlendi ( $p>0.05$ ). Gözler açık ve gözler kapalı olarak yapılan stabilite testinde, ayakkabılı ölçümlerde gözler açık alan değerinin daha iyi olduğu belirlenirken, ayakkabısız ölçümlerde gözler açık uzunluk ve hız değerlerinin daha iyi olduğu belirlendi $(p<0.05)$. Tartışma: Çalışmamızda, ayakkabının goalball sporcularında dengeyi pozitif yönde etkilemediği hatta ayakkabı varlığının goalball sporcularının dengelerini negatif etkilediği belirlendi. Aynı zamanda az gören goalball sporcularında bile görmenin denge üzerine pozitif etkileri olduğu çalışmamız ile belirlendi.

Anahtar Kelimeler: Sporlar, Görme-düşük; Denge; Ayakkabılar.

\section{ABSTRACT}

Purpose: The study was performed to determine the effects of the shoes and seeing (eyes opened, eyes closed) on balance in goalball players. Material and Methods: 9 female goalball players between 16-26 years, visually impaired between B1-B3 voluntarily participated. Equilibrium measurements were performed with the Human Body Equilibrium $360\left(\right.$ HUBER $360^{\circledR}$ ) electronic device. Measurements were done with shoes and without shoes. Results: It was determined that there was no difference in center, length and velocity values in the stability test measured with and without shoes $(p>0.05)$ and no difference in values measured eyes opened $(p>0.05)$. It was determined that eyes closed area value was less in shoeless position and in favour of measurement without shoes. No differences were observed on balance values on the right and left leg $(p>0.05)$. In the stability test having been done eyes-opened and eyesclosed, the area value with shoes and eyes-opened was better than measurements with shoe and eyes closed; the speed and length area values without shoes and eyes-opened were better than without shoes and eyes closed $(p<0.05)$. Conclusion: It was determined that the presence of shoes didn't affect the balance positively on goalball players and even affected the balance of goalball players negatively. In addition to these, in our study, it was determined that even in visually impaired goalball players, even seeing less has positive effects on balance.

Key Words: Sports; Vision-low; Balance; Shoes.

Sorumlu Yazar (Corresponding Author): Bihter AKINOĞLU e-mail: rgkardelen@yahoo.com ORCID ID: 0000-0002-8214-7895

Geliş Tarihi (Received): 24.12.2016; Kabul Tarihi (Accepted): 07.12.2017 
Denge, bir nesnenin veya bir insanın birbirini nötrleyen güçlerin sonunda devrilmeden durma hâli olarak tanımlanmakta olup; insanda duyusal, motor ve biyomekaniksel bileşenlerin koordinasyonunu gerektiren karmaşık bir süreçtir (Nashner Lewis, 1993). Dengenin kontrolü görsel, vestibüler ve somatosensoriyel sistemlerden gelen afferent bilgilerin entegrasyonu ile sağlanır (Foster ve diğ. 1996) Denge ve postural kontrolde görmenin önemi pek çok çalışmada belirtilmiştir (Nakata ve diğ. 2001; Sasaki ve diğ. 2002; Choy ve diğ. 2003). Görsel geri bildirim alamayan görme engelli bireylerde denge ve postural kontrol normal gören bireylere göre azalmış olabilir. Pek çok çalışma görme engeli olan bireylerde dinamik ve statik dengenin görme engelli olmayanlara göre daha kötü olduğunu ortaya koymuştur (PortfortsYeomans ve diğ. 1995). Görsel yetmezliği olan kişiler, postural düzgünlüğü korumak ve uzaydaki vücut pozisyonlarını ayarlamak için somatosensöriel ve vestibüler bilgilere daha fazla intiyaç duyarlar. Bu bireyler, zemin algısı ve çevreden gelen işitsel uyarılarla denge kontrolünü gerçekleştirirler (Anand ve diğ. 2003; Friedrich ve diğ. 2008). Engellilerin, engel durumu ve derecesine göre değişik branşlarda spor yapma olanakları bulunmaktadır. Engelli bireylerde spor güven duygusunu artırmakla birlikte kas kuvvetini de artırarak vücut dengesini olumlu yönde etkiler (O'Connell, 2000). Literatürde spor yapan görme engellilerde dengenin, gelişen bir takım motorik özellikler sonucunda spor yapmayan görme engellilere göre daha üst seviyeye ulaştığı rapor edilmiştir (Çalışkan ve diğ. 2006). Spor, görme engellilerde çevreden gelecek darbelere karşı zarar görme korkusunu azaltıp, bağımsız aktif hareketin artmasını sağlar (O'Connell, 2000). Görme engellilerin aktif olarak yaptığı spor branşları; goalball, torball, bowling, futbol, satranç ve atletizm olarak karşımıza çıkmakla beraber görme engellilerin yaptığı spor dallarından en yaygın olarak bilineni Goalball'dur (Çalışkan ve diğ. 2006).

Ayakkabı, vücut ile zemin arasında bağlantı görevi görür ve vücuda taktil ve propriyoseptif sistem vasıtasıyla somatosensoriyel girdi sağlar (Brenton-Rule ve diğ. 2011; Simeonov ve diğ. 2008). Bu girdiler alt ekstremitelerdeki kassal aktivasyonu değiştirip kişinin kinematiği ve iskelet dizilimi vasıtasıyla dengeyi etkiler (Simeonov ve diğ. 2008; Riskowski ve diğ. 2011). Bu bağlamda topuk yüksekliği, taban kalınlığı ve taban sertliği gibi ayakkabı özelliklerinin dengeyi etkilediği belirtilmiştir (Menant ve diğ. 2009; Whitney ve diğ. 2004). Literatürde görme engelli bireylerde dengeyle ilgili çeşitli değerlendirmeler yapılmış olmasına rağmen, ayakkabının dengeyi nasıl etkilediğine yönelik çalışmalara rastlanamamıştır.

Literatürde aynı zamanda sağlıklı bireylerle görme engelli bireylerin dengelerini karşılaştırarak yada sağlıklı bireylerin gözler açık ve kapalı dengelerini karşılaştırarak görme duyusunun denge üzerine etkisini inceleyen çalışmalar mevcuttur (Aydoğ ve diğ. 2006; Klavina ve diğ. 2014; Lieberman ve diğ. 2001). Ancak bizim bilgimize göre az gören bireylerde görmenin denge üzerine etkilerini inceleyen herhangi bir çalışma mevcut değildir.

Çalışmamızdaki hipotezimiz görme engelli goalball sporcularında ayakkabının ve görme duyusunun dengeyi pozitif yönde etkileyeceğidir. $\mathrm{Bu}$ nedenle çalışmanın amacı, görme engelli goalball sporcularında ayakkabının ve görmenin denge üzerine olan etkilerini araştırmaktır.

\section{GEREÇ VE YÖNTEM}

Çalışmamız, Gençlik ve Spor Bakanlığı (GSB), Spor Genel Müdürlüğü (SGM) Sağlık İşleri Dairesi Başkanlığı (SESAM-Sporcu Eğitimi ve Sağlık Araştırma Merkezi)'nda Mart-Mayıs 2016 tarihleri arasında gerçekleştirildi. Olguların çalışmaya alınma kriterleri; bilinen herhangi bir ortopedik veya sistemik problemi olmamak, cerrahi geçirmemiş olmak, görme engeli dışında herhangi bir sağlık problemi olmamak, çalışmada uygulanacak parametrelere aşina olmak ve daha önceden bu parametreleri deneyimlemiş olmak, en az 3 yıldır goalball sporu yapıyor olmak, çalışmaya katılmaya gönüllü olmak ve görme keskinlikleri B1-B3 seviyesi arasında olmaktı. Çalışma kriterlerine uyan ve çalışmaya katılmayı gönüllü olarak kabul eden 16-26 yaş aralığında görme keskinlikleri B1B3 arasında olan 9 bayan görme engelli goalball sporcusu çalışmaya dâhil edildi. [Görme engelli bireyler görme yetilerinin etkilenimine göre 3 gruba ayrılırlar, B1; Tamamen görmezler. Işığı algılayabilirler fakat hiçbir mesafeden el şeklini tanıyamazlar, B2; El şeklini algılayabilirler, fakat görme netliği 20/600 (\% 3) den düşüktür, B3; Görme açıları görsel alanda 5 dereceden daha azdır. Görme açıları 5-20 derece arasındadır. 20/600 (\% 3)-60/600 (\% 10) görme gücüne sahiptirler, şeklinde tanımlanır (O'Connell, 2000)]. Çalışmaya dâhil edilen sporculardan ikisinin görme yetisinin $B 1$; dördünün $B 2$; ve üçünün $B 3$ olduğu 
belirlendi. Çalışmaya dahil edilen sporcuların yaşlarının $19.55 \pm 3.81$ yıl, vücut ağırlıklarının $61.11 \pm 8.19 \mathrm{~kg}$, boy uzunluklarının $1.62 \pm 0.05 \mathrm{~m}$, vücut kütle indeksi değerlerinin $23.004 \pm 2.28 \mathrm{~kg} / \mathrm{m}^{2}$ ve spor yaşlarının $5.22 \pm 1.64$ yıl olduğu kaydedildi (Tablo 1). Çalışmaya dâhil edilen tüm sporcuların dominant tarafının sağ taraf olduğu sporculara

Çalışmanın yapılabilmesi için Ankara Yıldırım onay alındı $(11 / 47,318)$ ve çalışmaya başlamadan önce çalışmanın amacı, süreci, etkinliği hakkında sporcular bilgilendirildi ve gönüllülük esas alınarak

Değerlendirmeler sırasında sporcular spor kıyafetler giydi ve ayakkabısız ölçüm çıplak ayakla, ayakkabılı ölçüm ise, antrenmanda giydikleri aynı tip spor ayakkabı ile yapıldı. Tüm ölçümler bütün sporcular için günün aynı saatinde yapıldı. Tüm ölçümler aynı değerlendirici tarafından yapıldı. Gerçek ölçümlerden önce bütün sporculara deneme ölçümü yaptırıldı.

Denge ölçümleri Human Body Equilibrium 360 (HUBER $360^{\circledR}$ ) cihaz ile yapıldı. HUBER $360^{\circledR}$ dinamik ve statik denge ölçümü ve eğitiminde kullanılan, harekete duyarlı özel sensörler içeren ve kişiye görsel feedback veren bir ekran barındıran bilimsel çalışmalalrda kullanılan geçerli ve güvenilir elektronik bir cihazdır. HUBER $360^{\circledR}$ cihazı ile yapılabilen değerlendirmeler; stabilite, tek ayak üzerinde denge, yürüyüş, stabilizasyon limitleri, mobilite sınırlamaları, kuvvet ve koordinasyon olmak üzere 7 temel parametreden oluşur. Stabilite ve tek ayak üzerinde denge dışındaki değerlendirmelerde, ekrandaki avatar ve noktaların görsel geri bildirimle birleştirilerek değerlendirme yapılması gerektiğinden, çalışmamızda sadece stabilite ve tek ayak üzerinde denge parametreleri değerlendirildi. Değerlendirmeler ayakkabılı ve ayakkabısız olmak üzere iki şekilde ölçüldü. Ancak öğrenmenin etkisini kontrol etmek için rastgele 4 sporcunun ilk sorarak belirlendi. Beyazıt Üniversitesi Etik Kurulundan gerekli izin ve katılımcılardan yazılı onam alındı.

testi ayakkabılı yapılırken, geri kalan 5 sporcunun ilk testi çıplak ayakla gerçekleştirildi. Gözler açık çift ayak üzerinde denge, gözler kapalı çift ayak üzerinde denge, gözler açık sağ ve sol ayak üzerinde denge değerlendirmeleri ayakkabılı ve ayakkabısız olarak uygulandı. Ayakkabılı ve ayakkabısız denge ölçümleri arasında en az 30 dk'lık oturarak dinlenme arası verildi.

Stabilite değerlendirmesi gözler açık ve gözler kapalı olarak ayrı ayrı 50 sn boyunca, dik duruş posizyonunda gerçekleştirildi. Bu testte kişinin pozisyonunu ne derece koruyabildiği, merkezden uzaklaşması, merkez değişimi esnasında çizdiği uzunluk ve alan ile bu değişimlerdeki hız parametreleri değerlendirildi. Tek ayak üzerindeki denge; belirlenen bir noktaya önce sol sonra sağ ayak yerleştirilip boşta kalan ayak diz fleksiyonda askıda bekler pozisyon kullanılarak ölçüldü. Kişiden 30 sn boyunca dengesini destek almaksızın koruyabildiği kadar koruması istenerek askıda kalan ayağın belirlenen merkezden uzaklaşması, merkez değişimi esnasında çizdiği uzunluk ve alan parametreleri değerlendirildi (Çalışmada da kullanılan HUBER $360^{\circledR}$ cihazının değerlendirme http://international.chattgroup.com adresinden ulaşılabilir.).

İsatistiksel Analiz; Sporcuların ayakkabılı ve ayakkabısız ölçümlerinden elde edilen bütün veriler "SPSS (Statistical Package for Social Sciences Inc. Chicago, IL, USA) For Windows Release15.0" istatistiksel paket programı ile analiz edildi. Çalışmamızın istatistiklerinde ölçümle belirlenen değişkenler, ortalama \pm standart sapma $(X \pm S D)$ olarak ifade edildi. Sporculara ait ayakkabılı ve ayakkabısız ölçümlerinin sayısal değişkenlerinin karşılaştırılmasında Wilcoxon Signed Ranks Test kullanıldı. Tüm istatistiklerde $p$ anlamlılık değeri 0.05 olarak alındı (Sümbüloğlu, Sümbüloğlu, 1994).

Tablo 1. Sporcuların Yaş-Boy Uzunluğu-Vücut Ağırlığı-Vücut Kütle İndeksi-Spor Yaşı Değerleri $\mathrm{X} \pm \mathrm{SS}$

\begin{tabular}{cc}
\hline Yaş (Yıl) & $19.55 \pm 381$ \\
\hline Boy Uzunluğu $(\mathrm{m})$ & $1.62 \pm 0.05$ \\
\hline Vücut Ağırlığı $(\mathrm{Kg})$ & $61.11 \pm 8.19$ \\
\hline Vücut Kütle İndeksi $\left(\mathrm{Kg} / \mathrm{m}^{2}\right)$ & $23.00 \pm 2.28$ \\
\hline Spor Yaşı (yıl) & $5.22 \pm 1.64$
\end{tabular}




\section{SONUÇLAR}

Çalışmamız sonucunda ayakkabılı ve ayakkabısız olarak değerlendirilen stabilite testleri karşılaştırıldığında gözler açık ve gözler kapalı yapılan değerlendirmelerde merkez, uzunluk ve hız parametrelerinde farklılık olmadığı belirlendi ( $p>0.05)$. Ancak gözler kapalı yapılan değerlendirmede ölçülen alan değerlerinin ayakkabısız ve gözler kapalı olarak ölçülen alan değerlerine göre daha fazla olduğu ve ayakkabılı ölçüm aleyhine olduğu ( $p<0.05)$, gözler açık olarak ölçülen alan değerlerinde farklılık olmadığı belirlendi $(p>0.05)$. Sporcuların tek ayak üzerindeki denge sonuçları karşılaştırıldığında, ayakkabılı ve ayakkabısız sağ ve sol ayak üzerindeki dengeleri arasında farklılık görülmediği belirlendi $(p>0.05)$ (Tablo 2).

Sporcuların gözler açık ve gözler kapalı olarak ölçülen denge değerleri karşılaştırıldığında ise Ayakkabılı ölçümlerde gözler açık alan değerinin daha iyi olduğu belirlenirken $(p<0.05)$, merkez, hız ve uzunluk değerlerinde fark belirlenmedi ( $p>0.05$ ). Ayakkabısız ölçümlerde gözler açık uzunluk ve hız değerlerinin daha iyi olduğu belirlenirken $(p<0.05)$, diğer parametrelerde anlamlı fark olmadığı belirlendi ( $p>0.05)$ (Tablo 3).

Tablo 2. Sporcuların Gözler Açık-Gözler Kapalı Pozisyonda ve Tek Ayak Üzerinde Ayakkabılı ve Ayakkabısız Denge Değerlerinin Karşılaştırılması

\begin{tabular}{|c|c|c|c|c|c|c|}
\hline & & & $\begin{array}{c}\text { Ayakkabılı } \\
X \pm S S\end{array}$ & $\begin{array}{c}\text { Ayakkabısız } \\
X \pm S S\end{array}$ & $\mathrm{p}^{*}$ & Z \\
\hline \multirow{8}{*}{ Stabilite } & \multirow{4}{*}{ Gözler Açık } & $\begin{array}{l}\text { Merkez } \\
(\mathrm{cm})\end{array}$ & $14.94 \pm 15.21$ & $19.30 \pm 12.57$ & 0.67 & -0.415 \\
\hline & & $\begin{array}{l}\text { Uzunluk } \\
\text { (mm) }\end{array}$ & $665.64 \pm 122.66$ & $711.10 \pm 120,59$ & 0.37 & -0.889 \\
\hline & & $\begin{array}{l}\text { Alan } \\
\left(\mathrm{mm}^{2}\right)\end{array}$ & $355.32 \pm 322.12$ & $243.64 \pm 124.39$ & 0.11 & -1.599 \\
\hline & & $\begin{array}{l}\mathrm{H} ı \mathrm{z} \\
(\mathrm{mm} / \mathrm{sn})\end{array}$ & $13.31 \pm 2.45$ & $14.22 \pm 2.41$ & 0.37 & -0.889 \\
\hline & \multirow{4}{*}{$\begin{array}{l}\text { Gözler } \\
\text { Kapalı }\end{array}$} & $\begin{array}{l}\text { Merkez } \\
(\mathrm{cm})\end{array}$ & $17.23 \pm 13.56$ & $11.16 \pm 10.45$ & 0.37 & -0.889 \\
\hline & & $\begin{array}{l}\text { Uzunluk } \\
(\mathrm{mm})\end{array}$ & $819.68 \pm 236.18$ & $732.37 \pm 121.74$ & 0.17 & -1.362 \\
\hline & & $\begin{array}{l}\text { Alan } \\
\left(\mathrm{mm}^{2}\right)\end{array}$ & $537.43 \pm 330.73$ & $361.74 \pm 212.60$ & $0.02^{*}$ & -2.192 \\
\hline & & $\begin{array}{l}\mathrm{HIz} \\
(\mathrm{mm} / \mathrm{sn})\end{array}$ & $16.39 \pm 4.72$ & $14.64 \pm 2.43$ & 0.17 & -1.362 \\
\hline \multirow{6}{*}{$\begin{array}{l}\text { Tek Ayak } \\
\text { Üzerinde } \\
\text { Denge }\end{array}$} & \multirow{3}{*}{$\begin{array}{l}\text { Sol Ayak } \\
\text { Üzerinde } \\
\text { Denge }\end{array}$} & $\begin{array}{l}\text { Merkez } \\
(\mathrm{cm})\end{array}$ & $11.65 \pm 7.10$ & $19.16 \pm 11.35$ & 0.06 & -1.836 \\
\hline & & $\begin{array}{l}\text { Uzunluk } \\
(\mathrm{mm})\end{array}$ & $\begin{array}{c}3403.76 \pm \\
1575.20\end{array}$ & $\begin{array}{c}3754.54 \pm \\
1524.84\end{array}$ & 0.76 & -0.296 \\
\hline & & $\begin{array}{l}\text { Alan } \\
\left(\mathrm{mm}^{2}\right)\end{array}$ & $\begin{array}{c}11068,28 \pm \\
16666.35\end{array}$ & $\begin{array}{c}13150.98 \\
\pm 13278.41 \\
\end{array}$ & 0.44 & -0.770 \\
\hline & \multirow{3}{*}{$\begin{array}{l}\text { Sağ Ayak } \\
\text { Üzerinde } \\
\text { Denge }\end{array}$} & $\begin{array}{l}\text { Merkez } \\
(\mathrm{cm})\end{array}$ & $10.49 \pm 11.05$ & $11.96 \pm 10.47$ & 0.76 & -0.296 \\
\hline & & $\begin{array}{l}\text { Uzunluk } \\
(\mathrm{mm})\end{array}$ & $\begin{array}{c}3448.36 \pm \\
898.34\end{array}$ & $\begin{array}{c}3914.16 \pm \\
2059.23\end{array}$ & 0.44 & -0.770 \\
\hline & & $\begin{array}{l}\text { Alan } \\
\left(\mathrm{mm}^{2}\right)\end{array}$ & $\begin{array}{c}6965.90 \pm \\
2280.10\end{array}$ & $\begin{array}{c}10679.87 \pm \\
10276.08\end{array}$ & 0.44 & -0.770 \\
\hline
\end{tabular}

\footnotetext{
* Wilcoxon Signed Ranks Test, $\mathrm{X} \pm$ SS: Ortalama \pm Standart Sapma
} 
Tablo 3. Sporcuların Ayakkabılı ve Ayakkabısız Gözler Açık-Gözler Kapalı Pozisyonda Denge Değerlerinin Karşılaştırılması

\begin{tabular}{|c|c|c|c|c|c|c|}
\hline & & & $\begin{array}{l}\text { Gözler } \\
\text { Açık }\end{array}$ & Gözler Kapalı & $p^{*}$ & Z \\
\hline \multirow{8}{*}{ Stabilite } & \multirow{4}{*}{$\begin{array}{l}\text { Ayakkabılı } \\
X \pm S S\end{array}$} & $\begin{array}{l}\text { Merkez } \\
(\mathrm{cm})\end{array}$ & $14.94 \pm 15.21$ & $17.23 \pm 13.56$ & 0.06 & -1.836 \\
\hline & & $\begin{array}{l}\text { Uzunluk } \\
(\mathrm{mm})\end{array}$ & $665.64 \pm 122.66$ & $819.68 \pm 236.18$ & 0.11 & -1.599 \\
\hline & & $\begin{array}{c}\text { Alan } \\
\left(\mathrm{mm}^{2}\right)\end{array}$ & $355.32 \pm 322.12$ & $537.43 \pm 330.73$ & $0.03^{*}$ & -2.073 \\
\hline & & $\begin{array}{c}\mathrm{H} I \mathrm{z} \\
(\mathrm{mm} / \mathrm{sn})\end{array}$ & $13.31 \pm 2.45$ & $16.39 \pm 4.72$ & 0.11 & -1.599 \\
\hline & \multirow{4}{*}{$\begin{array}{l}\text { Ayakkabısız } \\
X \pm S S\end{array}$} & $\begin{array}{l}\text { Merkez } \\
(\mathrm{cm})\end{array}$ & $19.30 \pm 12.57$ & $11.16 \pm 10.45$ & 0.21 & -1.244 \\
\hline & & $\begin{array}{l}\text { Uzunluk } \\
(\mathrm{mm})\end{array}$ & $711.10 \pm 120.59$ & $732.37 \pm 121.74$ & $0.02^{*}$ & -2.310 \\
\hline & & $\begin{array}{l}\text { Alan } \\
\left(\mathrm{mm}^{2}\right)\end{array}$ & $243.64 \pm 124.39$ & $361.74 \pm 212.60$ & 0.08 & -1.718 \\
\hline & & $\begin{array}{c}\mathrm{H} I \mathrm{z} \\
(\mathrm{mm} / \mathrm{sn})\end{array}$ & $14.22 \pm 2.41$ & $14.64 \pm 2.43$ & $0.02^{*}$ & -2.310 \\
\hline
\end{tabular}

\section{TARTIŞMA}

Görme engelli goalball sporcularında ayakkabının ve görmenin denge üzerine olan etkilerini araştırmak amacıyla gerçekleştirdiğimiz çalışmamız sonucunda ayakkabının goalball sporcularında dengeyi etkilemediği ve az gören goalball sporcularında bile görmenin denge üzerine pozitif etkileri olduğu belirlendi.

Denge, birbirini nötrleyen güçlerin sonunda bir nesnenin veya bir insanın devrilmeme durumu olarak tanımlanan; duyusal, motor ve biyomekaniksel bileşenlerin koordinasyonunu gerektiren karmaşık bir süreçtir (Nashner Lewis, 1993). Bazı araştırmacılar görme bozukluğu olan kişilerin alt ekstremite hareketlerini düzelterek postural stabilite kontrolüne katkıda bulunulabileceğini belirtmişlerdir (Hsu ve diğ. 2007; Krishnamoorthy ve diğ. 2005). Biz de bu açıklamayı temel alarak ayakkabı varlığının posturü ve dengeyi olumlu etkileyeceğini düşündük. $\mathrm{Bu}$ nedenle, çalışmamızda hipotezlerimizden biri Goalball sporcularında ayakkabının denge üzerine pozitif etkileri olacağı yönündeydi.

Güçhan ve ark. 70 sağlıklı birey üzerinde yapmış oldukları çalışmalarında dengeyi ayakkabılı ve ayakkabısız olarak karşılaştırmış ve ayakkabılı dengenin ayakkabısız dengeden daha iyi olduğu sonucuna varmışlardır. Ancak bu çalışmada ayakta stabilite sağlanmasını gerektiren aktivitelerde ayakkabının fonksiyonellik açısından olumlu etkilere sahip olduğunu, fakat ayakkabı nedeniyle fizyolojik ya da kompansatuar hareketlerin engellenebildiği aktivitelerde ise ayakkabının olumsuz etkiye yol açtığını belitmişlerdir (Güçhan ve diğ. 2014). Bizim çalışmamızda sporcuların ayakkabılı ve ayakkabısız dengeleri karşılaştırıldığında birçok parametre birbirine benzer olmasına rağmen, gözler kapalı ölçülen alan değerlerinin ayakkabısız ölçümler lehinde olması nedeniyle ayakkabısız dengelerinin daha iyi olduğu söylenebilir. Bu sonucun çalışmaya aldığımız bireylerin sporcu olmaları, görme engelli olmaları ve aynı zamanda Güçhan ve ark. nın belirttiği gibi görme engelleri nedeniyle kompansatuar mekanizmalara ihtiyaç duymalarından kaynaklandığını düşünmekteyiz.

Aydoğ ve ark. yaptıkları çalışmada görme engeli bulunmayan sedanterler, görme engeli bulunan sedanterler ve görme engelli atletlerde dinamik stabiliteyi değerlendirmişlerdir. Görme engeli olmayan bireylerin gözü açık denge skorunun en iyi skor olduğu belirlenmiştir. Çalışmanın başlıca bulguları dinamik dengenin görsel sistemden etkilendiğidir (Aydoğ ve diğ. 2006). Biz de yaptığımız araştırma sonucunda sporcuların gözleri açık durumda dengelerinin daha iyi olduğunu belirledik. Bu sonuçlarımız literatürdeki; dengenin görsel sistemden etkilendiği bilgisi ile paralellik göstermekte ve görme duyusu az olsa bile denge üzerinde etkili olduğunu ortaya koymaktadır. Çalışmamızın bu sonucu ile görme duyusunun dengeyi pozitif yönde etkileyeceği ikinci hipotezimiz doğrulanmaktadır. 
Yaptığımız araştırmalara göre daha önce görme engelli bireylerde ayakkabılı ve ayakkabısız dengeyi karşılaştıran bir çalışmaya rastlamadık. Araştırmamıza en yakın gördüğümüz çalışma; Tomomitsu ve ark.'larının az görenlerle normal görme yetisine sahip kişileri kıyasladığı çalışmasıdır (Tomomitsu ve diğ. 2013). Bu çalışmada görme engellilerde zemin ile denge arasındaki ilişki incelenirken, biz de görme engellilerde ayakkabılı ve ayakkabısız duruş esnasında gözler açık ve kapalı durumdayken dengenin nasıl etkilediğini belirlemek amacıyla ölçüm sonuçlarını karşılaştırdık. Çalışmamız sonucunda ayakkabı varlığının goalball yapan sporcularda dengeyi pozitif yönde etkilemediğini belirledik. Çalışmamızın diğer sonucu ise az gören goalball sporcularında gözler açık dengenin gözler kapalı dengeden daha iyi olduğudur. Literatürü destekleyecek şekilde bu sonuç; görsel komponentin dengede ne kadar önemli bir parametre olduğunu ve az görmenin bile denge üzerinde etkili olduğunu gösterdi.

Çalışmamızda hipotezimiz ayakkabı varlığının ayakta yük dağılımını olumlu etkilediği ve bunun eklem dizilimi üzerine olumlu etkisi olduğuydu. Sonuçların beklentimizden farklı çıkmasının; test ettiğimiz görme engelli bireylerin goalball sporcusu olmalarıyla, sporcuların görme engelleri nedeniyle kompansatuar mekanizmalara intiyaç duymalarıla ve goalball sporunun görme engellilerde dengeyi arttırmak amacıyla bir rehabilitasyon protokolü olarak kullanılmasıyla bağlantılı olduğunu düşünmekteyiz. Çalışmamızın limitasyonu çalışmaya katılan denek sayımızın az olmasıdır. Bu bağlamda denek sayısı arttırılarak ve sedanter görme engelli bireyler veya başka spor branşından görme engellilerle karşılaştırma yapılan çalışmalara intiyaç duyulmaktadır.

$\mathrm{Bu}$ çalışmanın çıkarımı olarak görme engelli bireylerde ayakkabı kişilerin dengesini pozitif yönde etkilememektedir hatta; ayakkabı sporcuların dengesini negatif yönde etkilemektedir. Bu nedenle çalışmamız sonucunda bu sporcularda hangi ayakkabı tipi ile dengelerinin daha iyi olduğunu araştıracak ve bu sonuçlara göre sporculara uygun ayakkabı önerecek çalışmalara intiyaç olduğunu düşünmekteyiz. Aynı zamanda çalışmamız sonucunda goalball gibi düzenli spor yapan görme engelli bireylerde bile görme duyusunun kişilerin dengelerini etkileyen önemli bir parametre olduğu yeniden gösterilmiştir.

\section{Kaynaklar}

Anand, V., Buckley, F. G, Scally, A., \& Elliott, D. B. (2003). Postural stability in the elderly during sensory pertubations and dual tasking: the influence of refractive blur. Invest Ophthalmol Vis Sci, 44, 2885-9.

Aydoğ, E., Aydoğ, S. T., Cakci, A., \& Doral, M. N. (2006). Dynamic postural stability in blind athletes using the biodex stability system. Int J Sports Med, 27(5), 415-8.

Brenton-Rule, A., Bassett, S., Walsh, A., \& Rome, K. (2011). The evaluation of walking foot wear on postural stability in healthy older adults: an exploratory study. Clin Biomech (Bristol, Avon), 26, 885-887.

Choy, N. L., Brauer, S., \& Nitz, J. (2003). Changes in postural stability in women aged 20 to 80 years. $J$ Gerontol A Biol Sci Med Sci, 58, 525-530.

Çalışkan, E., Pehlivan, A., İnal, S., Dane, Ş., \& Akar, S. (2006). Goalball sporunun ve hareket eğitiminin görme engelli çocukların fiziksel uygunluk üzerine etkilerinin değerlendirilmesi. Journal of Physical Education and Sport Sciences, 8(3), 3-14.

Foster, E. C., Sveistrup, H., \& Woollacott, M. H. (1996). Transitions in visual proprioception: a cross-sectional developmental study of the effect of visual flow on postural control. J Mot Behav, 28, 101-112.

Friedrich, M., Grein, H. J., Wicher, C., Schuetze, J., Mueller, A., \& Lauenroth, A. (2008). Influence of pathologic and simulated visual dysfunctions on the postural system. Exp Brain Res, 86(2), 305-14.

Güçhan, Z., Özaydınlı, E. I., Demirel, S., Yüzlü, V., \& Bek, N. (2014). Ayakkabı kullanımı ile ayak deformiteleri, denge ve fonksiyonel performans arasındaki ilişkinin incelenmesi. Journal of Exercise Therapy and Rehabilitation, 1(1), 35-42.

Hsu, W. L., Scholz, J. P., Schoner, G., Jeka, J. J., \& Kiemel, T. (2007) Control and estimation of posture during quiet stance depends on multi joint coordination. $J$ Neurophysiol, 97(4), 3024-35.

http://international.chattgroup.com/sites/default/files/user_gui de_huber_360_-_1786.pdf (Ulaşılabilir link), Erişim tarihi: 30.04.2016

Klavina, A., \& Jekabsone, I. (2014). Static balance of persons with intellectual disabilities, visual impairment and without disabilities. European Journal of Adapted Physical Activity, 7(1), 50-57.

Krishnamoorthy, V., Yang, J. F., \& Scholz, J. P. (2005). Joint coordination during quiet stance: effects of vision. Exp Brain Res,164(1), 1-17.

Lieberman, L. J., \& McHugh, B. E. (2001). Health re1ated fitness of children with visual impairments and blindness. $J$ Vis Impair Blind, 95(5), 272-286.

Menant, J. C., Steele, J. R., Menz, H. B., Munro, B. J., \& Lord, S. R. (2009). Effects of walking surfaces and foot wear on temporospatial gait parameters in young and older people. Gait Posture, 29, 392-397.

Nakata, H., \& Yabe, K. (2001). Automatic postural response systems in individuals with congenital total blindness. Gait Posture, 14, 36-43. 
Nashner, L. M. (1993). Practical biomechanics and physiology of balance. In G.P. Jacobson, C.W. Newman \& J. M. Kartush (Eds), Handbook of balance function testing (pp. 261-79). St. Louis: Mosby Yearbooks.

O'Connell, M. (2000). The effect of brailling and physical guidance on the self efficacy of children who are blind (Unpublished master'sthesis). State University of New York College at Brockport, NY.

Portforts-Yeomans, C. V., \& Riach, C. L. (1995). Frequency characteristics of postural control of children with and without visual impairment. Dev Med Child Neurol, $37,456-463$.

Riskowski, J., Dufour, A. B., \& Hannan, M. T. (2011). Arthritis, foot pain and shoe wear: Current musculoskeletal research on feet. Curr Opin Rheumatol, 23,148-155.

Sasaki, O., Usami, S., Gagey, P.M., Martinerie, J., VanQuyen, M., \& Arranz, P. (2002). Role of visual input in nonlinear postural control system. Exp Brain Res, 147,17.

Simeonov, P., Hsiao, H., Powers, J., Ammons, D., Amendola, A., Kau, T. Y.,\& et al. (2008). Foot wear effects on walking balance at elevation. Ergonomics, 51, 1885-1905.

Sümbüloğlu, K., \& Sümbüloğlu, V. (1994). Biyoistatistik. Ankara: Özdemir Yayıncılık.

Tomomitsu, M. S., Alonso, A. C., Morimoto, E., Bobbio, T. G., \& Greve, J. (2013). Static and dynamic postural control in low-vision and normal-vision adults. Clinics, 68(4), 517521

Whitney, S. L., \& Wrisley, D. M. (2004). The influence of foot wear on timed balance scores of the modified clinical test of sensory interaction and balance. Arch Phys Med Rehabil, 85, 439- 443. 
